\title{
Algorithm to retrieve the melt pond fraction and the spectral albedo of Arctic summer ice from satellite optical data
}

\author{
E. Zege a , A. Malinka ${ }^{\text {a, } *}$, I. Katsev ${ }^{\text {a }}$, A. Prikhach ${ }^{\text {a }}$, G. Heygster ${ }^{\text {b }}$, L. Istomina ${ }^{\text {b }}$, G. Birnbaum ${ }^{\text {c }}$, P. Schwarz ${ }^{\text {d }}$ \\ a Institute of Physics, National Academy of Sciences of Belarus, 220072, Pr. Nezavisimosti 68, Minsk, Belarus \\ b Institute of Environmental Physics, University of Bremen, O. Hahn Allee 1, D-28359 Bremen, Germany \\ c Alfred Wegener Institute, Helmholtz Centre for Polar and Marine Research, Bussestraße 14, D-27570 Bremerhaven, Germany \\ d Department of Environmental Meteorology, University of Trier, Behringstraße 21, D-54286 Trier, Germany
}

\section{A R T I C L E I N F O}

\section{Article history:}

Received 23 July 2014

Received in revised form 11 March 2015

Accepted 13 March 2015

Available online 3 April 2015

\section{Keywords:}

Melt ponds

Sea-ice

Albedo

Arctic

Remote sensing

\begin{abstract}
A B S T R A C T
A new algorithm to retrieve characteristics (albedo and melt pond fraction) of summer ice in the Arctic from optical satellite data is described. In contrast to other algorithms this algorithm does not use a priori values of the spectral albedo of the sea-ice constituents (such as melt ponds, white ice etc.). Instead, it is based on an analytical solution for the reflection from sea ice surface. The algorithm includes the correction of the sought-for ice and ponds characteristics with the iterative procedure based on the Newton-Raphson method. Also, it accounts for the bi-directional reflection from the ice/snow surface, which is particularly important for Arctic regions where the sun is low. The algorithm includes an original procedure for the atmospheric correction, as well. This algorithm is implemented as computer code called Melt Pond Detector (MPD). The input to the current version of the MPD algorithm is the MERIS Level 1B data, including the radiance coefficients at ten wavelengths and the solar and observation angles (zenith and azimuth). Also, specific parameters describing surface and atmospheric state can be set in a configuration input file. The software output is the map of the melt ponds area fraction and the spectral albedo of sea-ice in HDF5 format. The numerical verification shows that the MPD algorithm provides more accurate results for the light ponds than for the dark ones. The spectral albedo is retrieved with high accuracy for any type of ice and ponds.
\end{abstract}

(c) 2015 Elsevier Inc. All rights reserved.

\section{Introduction}

Knowledge of properties of the Arctic ice cover is of great importance for modeling and predicting the global climate and for ship navigation in the Arctic Ocean (Serreze et al., 2000; Shindell \& Faluvegi, 2009; Untersteiner, 1990). Extensive melting in the summer affects the entire sea-ice structure; particularly, it changes the upper layer of ice, producing the melt ponds on its surface (Perovich et al., 2009; Polashenski, Perovich, \& Courville, 2012). Melt ponds change the radiative balance in the Arctic, because they drastically reduce the ice albedo and, therefore, increase the flux of absorbed sun light energy and speed up the melting process (positive feedback mechanism) (Curry, Schramm, \& Ebert, 1995). Melt ponds are not just one of the most important factors affecting the ice albedo, but also one of the most variable (Barry, 1996; Eicken, Grenfell, Perovich, Richter-Menge, \& Frey, 2004). Ice albedo, in its turn, is among the most crucial parameters, which govern the climate processes in the Arctic (Køltzow, 2007; Pirazzini, 2008). In particular, changes of the ice albedo modulate the strength of the subpolar westerlies and storm tracks (Dethloff et al., 2006). It is also important that with decrease of the ice thickness the ice pack becomes more

\footnotetext{
* Corresponding author.

E-mail address: mal@light.basnet.by (A. Malinka).
}

sensitive to the ice-albedo feedback (Perovich, Richter-Menge, Jones, \& Light, 2008; Pistone, Eisenmann, \& Ramanathan, 2014; Serreze, Barrett, \& Cassano, 2011).

Therefore, the availability of temporally and spatially continuous data on sea-ice albedo and melt pond fraction products is crucial (see, e.g. Schröder, Feltham, Flocco, \& Tsamados, 2014). These products can serve as an input for Global Climate Models or be utilized in studies of melt evolution mechanisms (Flocco, Feltham, \& Turner, 2010; Flocco, Schroeder, Feltham, \& Hunke, 2012; Hunke, Hebert, \& Lecomte, 2013; Lüpkes et al., 2013).

The objective of this work is to develop an algorithm to retrieve summer ice albedo and the area fraction of melt ponds on sea ice from data of optical satellite sensors.

The MPD algorithm for retrieval of the ice albedo and melt pond fraction from satellite measurements is based on field measurements of the reflectance spectra of ice and ponds (Istomina, Nicolaus, \& Perovich, 2013; Polashenski et al., 2012). Other known algorithms of melt pond fraction retrieval from the optical satellite data (Rösel et al., 2012; Tschudi, Maslanik, \& Perovich, 2008) use the a priori fixed spectral reflection coefficients for different pixel constituents, such as snow, bare ice, melt ponds, and open water. However, the physical properties of these constituents, e.g. the ice or snow thickness and the typical grain size, the pond depth, and the albedo of pond bottom, are highly variable, 
and so are their optical properties. This variability can result in substantial errors in pond fraction retrieval. For example, the dark ice may result in overestimation of the melt pond fraction. Conversely, the light pond can be misclassified as unponded ice. At the same time the optical properties (e.g., the reflection coefficients) of ice and ponds have different spectral behavior. So, using a sufficient number of spectral channels, we can set, in principle, the problem not just to retrieve their fractions, but also to estimate some of their characteristics (e.g. the optical thicknesses of ice, the pond depth, the albedo of its bottom etc.). In this work we are making the first attempt to develop an algorithm for pond fraction retrieval from the satellite data without a priori fixed values of the spectral reflection coefficients of the pixel constituents and with simultaneous estimation of ponds and ice properties.

The second feature of the proposed MPD algorithm is that it accounts for bi-directional reflectance of the ice/snow surface. This feature is especially important in the Arctic where the sun is low and the light incidence is oblique (Zege et al., 2011). Particularly, the Fresnel reflection from melt pond surface (glint) at oblique incidence is very high. At the common geometry of measurements, when the observation is not much different from nadir, this glint is not seen from a satellite, but it contributes significantly to the albedo value. It is one more reason why the Lambertian approximation is not suitable for this problem. Moreover, using the albedo instead of the radiance coefficient (bi-directional reflectance distribution function - BRDF) can lead to unrealistic results.

The third specific feature of the MPD algorithm is the procedure of the atmospheric correction of the satellite data, included directly into the iterative retrieval process (see Section 2.3.1).

\section{Retrieval algorithm}

\subsection{Physical and optical properties of sea ice with melt ponds}

The basis of the algorithm is the relationship between physical characteristics of melting ice and measured reflectance properties. Systematic investigations of reflection characteristics of Arctic summer ice have been carried out throughout the 20th century (Doronin, 1970; Grenfell \& Maykut, 1977; Light, 2010; Mobley et al., 1998; Nazintsev, 1964; Perovich, 1996). A significant contribution to our knowledge was made in the recent years by the Tara drift (Heygster et al., 2012; Nicolaus et al., 2010) and by the Polarstern cruise ARK-27-3 (Boetius et al., 2013). The seasonal changes of the Multi-Year Ice (MYI) structure and reflection, as well as the melt pond emergence and evolution during Arctic summer, are carefully traced in the paper of Perovich, Grenfell, Light, and Hobbs (2002) on the base of the long-term observations. The following pattern can be picked out from this work.

During May the total albedo does not change significantly, being quite high due to the snow cover. Then in June, over several days rapid decrease of albedo takes place because of extensive snow melting. Melt water is accumulated in depressions on the ice surface, forming melt ponds and leaving the drained surface. The latter is covered by small (several $\mathrm{mm}$ ) pieces of ice. At first glance this cover may look similar to snow. It is called 'white ice' (Perovich, 1996). In contrast to snow, white ice is characterized by the larger typical grain size and physical density (typical microphysical/optical parameters can be found in Light, Eicken, Maykut, and Grenfell (1998)). Ice melting and pond formation result in albedo decrease with strong spatial variability. The melting period lasts usually from mid-June to mid-August. Then, from the end of August to early September the freezing begins and the albedo increases, reaching its winter values after a regular snowfall. The months indicated here were typical for the Beaufort and Chukchi seas at the end of the 20th-the beginning of the 21st centuries (Perovich et al., 2002). Nowadays the melt onset has moved to earlier time (in May) in this region (Markus, Stroeve, \& Miller, 2009). For regions located at higher latitudes the melting period starts as late as beginning July and is considerably shorter than at the southern latitudes.
The white ice is the bare ice with a substantial surface scattering layer that provides stable high reflectance. As measurements show (Perovich et al., 2002), the spectral albedo of the white ice is comparatively stable and varies in the range $0.75-0.8$ in the blue-green region of the spectrum (at 450-500 nm). Tschudi et al. (2008) write: "The white ice category rose from the observation of bare ice at Barrow that had a white appearance due to the presence of a surface scattering layer. This layer was typically a few centimeters thick and consisted of small fragments of deteriorated ice."

In fact, the optical parameters of white ice are determined by the following main features: the ice grains have arbitrary shapes and sizes, much greater than the wavelength of the visible light. Thus, the main results of snow optics (Kokhanovsky \& Zege, 2004) can also be used to describe the optics of white ice and for remote sensing of sea-ice. Further development of optics of snow and ice has been achieved recently with the use of the model of random mixture (Malinka, 2014).

The reflection properties of a layer are described by the spectral bidirectional reflectance distribution function (BRDF) $R\left(\theta, \theta_{0}, \varphi, \lambda\right.$ ), where $\theta$ and $\theta_{0}$ are the zenith angles of the observation and illumination directions, respectively, and $\varphi$ is the azimuth angle between them. Hereafter, we will omit the variables $\left(\theta, \theta_{0}, \varphi, \lambda\right)$ of function $R$ for brevity. The reflection of the white ice as well as the reflection of a snow covered ice floe (Zege et al., 2011) can be described using the asymptotic solution for optically thick weak absorbing scattering media (Kokhanovsky \& Zege, 2004). The following solution for the BRDF $R_{\infty}$ of a semiinfinite weak absorbing layer is described in Zege, Ivanov, and Katsev (1991):

$R_{\infty}=R_{\infty}^{0} \exp \left[-4 q \gamma g(\theta) \mathrm{g}\left(\theta_{0}\right) / R_{\infty}^{0}\right]$

where $R_{\infty}^{0}$ is the BRDF of the semi-infinite non-absorbing layer with the same scattering phase function; $g(\theta), q$ and $\gamma$ are equal to:

$g(\theta)=\frac{3}{7}(1+2 \cos \theta)$

$q=\frac{1}{3\left(1-\omega_{0} g\right)}$

$\gamma=\sqrt{\left(1-\omega_{0}\right)\left(1-\omega_{0} g\right)}$

where $\omega_{0}$ is the single scattering albedo (the photon survival probability) and $g$ is the mean cosine of the scattering phase function.

Eq. (1) was used in (Zege et al., 2011) for snow remote sensing (Wiebe, Heygster, Zege, Aoki, \& Hori, 2013). But unlike snow cover, when a layer with depth of a few $\mathrm{cm}$ is optically very thick, an ice floe is more or less translucent and its optical thickness $\tau_{w i}$ is the main parameter that determines its reflection and transmission. In this case, using the asymptotic solution for optically thick layers (Zege et al., 1991), one can get:

$R=R_{\infty}^{0} \frac{\sinh \left[\gamma\left(\tau_{w i}+4 q\left[1-g(\theta) g\left(\theta_{0}\right) / R_{\infty}^{0}\right]\right)\right]}{\sinh \left[\gamma\left(\tau_{w i}+4 q\right)\right]}$.

The values $R_{\infty}^{0}, \omega_{0}$, and $g$ (and consequently, $q$ and $\gamma$ ) are calculated with the use of the model of random mixture (Malinka, 2014), which relates the inherent optical properties of a stochastic medium to the complex refractive index and the effective grain size $a_{\text {eff. }}$.

In Eqs. (2)-(5) the values $R_{\infty}^{0}, g$, and $\tau_{w i}$ do not depend practically on wavelength in the considered spectral region. The spectral dependence of reflectance is defined by the single scattering albedo $\omega_{0}$, determined by the complex refractive index of ice (Warren \& Brandt, 2008) and the absorption of possible pollutants. The analysis of field data shows (Istomina, Heygster, et al., 2013) that if one consider ice disposed far from the coastline, the spectral dependence of reflectance is described 
well by adding the absorption of yellow organic pigments from the seawater (Bricaud, Morel, \& Prieur, 1981).

In the blue-green range of the spectrum (450-500 nm), where neither ice nor yellow substance absorb light, the model of random mixture gives the values:

$q \approx 1, \quad \gamma \approx 0$.

Within this limit formula (5) turns into:

$R=R_{\infty}^{0}-\frac{4 g(\theta) \mathrm{g}\left(\theta_{0}\right)}{\tau_{w i}+4}$.

Using Eq. (7), it is easy to get the albedo in this region of the spectrum. The albedo at direct incidence (the direct-hemispherical reflectance or 'black sky' albedo) $r\left(\theta_{0}\right)$ equals:

$r\left(\theta_{0}\right)=1-\frac{4 g\left(\theta_{0}\right)}{\tau_{w i}+4}$

The albedo at diffuse incidence (the bi-hemispherical reflectance or 'white sky' albedo) $r$ equals:

$r=\frac{\tau_{w i}}{\tau_{w i}+4}$

Thus, the BRDF of white ice is completely determined by the optical depth $\tau_{w i}$ of a layer, the mean effective grain size $a_{e f f}$, and the absorption coefficient $\alpha_{y p}$ of yellow pigments, which could arrive in the white ice due to organics from the seawater. These parameters constitute the vector $X_{i c e}=\left(\tau_{w i}, a_{e f f}, \alpha_{y p}\right)$ (see Table 1$)$.

Melt ponds can differ in color from dark gray to light blue. In general, melt ponds have a width from the order of meters to hundreds of meters and a depth from several centimeters to tens of centimeters. However, the apparent color of a melt pond practically does not depend on the water depth, but mainly on the optical thickness of the ice underneath. Therefore, the melt pond type can evolve during the melt season as the underlying ice becomes thinner. Most often, the general separation of the melt ponds into dark and light blue ponds corresponds to ponds on first year or thinner ice floes and on multiyear or thicker ice floes, respectively. However, there are ponds, which cannot be attributed to a particular category, or even ponds, which have a portion with a light bottom and a portion with a dark bottom (Perovich et al., 2002).

To describe the light reflection by melt ponds we use the following model assumptions:

1. Melt water is clear, i.e. there are no pollutants, which could change its absorption spectrum. Actually, this assumption is not necessary, because any absorbing contaminant with the known absorption spectrum can be included into the model straightforwardly. However, the possibility of satellite retrieval of the contaminant concentration in melt ponds is a question of future work. At this stage we do not consider any contaminants in melt water. This assumption is reasonable at least for cases when ice is far enough from the coastline and not affected by river run-off.

Table 1

Characteristics of ponds and ice, used in the modeling. All characteristics are given at wavelength $550 \mathrm{~nm}$, except absorption of yellow pigments, which is given at $390 \mathrm{~nm}$.

\begin{tabular}{clcl}
\hline Type & Characteristics & Comments \\
\hline Pond & $X_{\text {pond }}$ & $\tau_{p}$ & Optical thickness of the water layer in the pond \\
& & $\sigma_{\text {ice }}$ & Transport scattering coefficient of the underlying ice \\
& & $\tau_{i c e}$ & Optical thickness of the underlying ice \\
Ice & $X_{\text {ice }}$ & $\tau_{w i}$ & Effective optical thickness of white scattering layer \\
& & $a_{\text {eff }}$ & Effective grain size in white scattering layer (in $\mu \mathrm{m})$ \\
& & $\alpha_{y p}$ & Absorption coefficient of yellow pigments (in $\mathrm{m}^{-1}$ ) \\
\hline
\end{tabular}

2. As the melt ponds depth is much smaller than their width, we will consider the pond as an infinite layer of water, neglecting the sidelong reflection, but considering only reflection by the pond bottom.

3. The reflection from the pond bottom is isotropic (Lambert law). Deviation from the Lambert law will cause a negligible change in the angular distribution of light going out from the melt pond because of multiple reflections between pond surface and bottom.

With these assumptions after somewhat lengthy but straightforward calculations one can get the following expression for the pond BRDF:

$R=\frac{\pi}{\mu_{0}} R^{F}\left(\mu_{0}\right) \delta\left(\mu-\mu_{0}\right) \delta(\varphi)+\frac{T^{F}\left(\mu_{0}\right) T^{F}(\mu) \exp \left(-\tau_{p} / \mu_{t}^{0}-\tau_{p} / \mu_{t}\right) A_{b}}{n^{2}\left(1-f_{i n}\left(\tau_{p}\right) A_{b}\right)}$

where $\mu=\cos \theta, \mu_{0}=\cos \theta_{0}$ are the cosines of the observation and incidence zenith angles, $\mu_{t}$ and $\mu_{t}^{0}$ are the cosines of the corresponding angles after refraction:

$\mu_{t}^{0}=\frac{1}{n} \sqrt{n^{2}-1+\mu_{0}^{2}}, \quad \mu_{t}=\frac{1}{n} \sqrt{n^{2}-1+\mu^{2}}$,

$n$ is the real part of the refractive index of water; $R^{F}\left(\mu_{0}\right)$ and $T^{F}\left(\mu_{0}\right)$ are the Fresnel reflection and transmission coefficients, respectively, $\delta(x)$ is the Dirac delta-function, $\tau_{p}$ is the melt pond optical depth, $A_{b}$ is the albedo of the pond bottom, $f_{i n}\left(\tau_{p}\right)$ is a function defined as:

$f_{\text {in }}(\tau)=2 \int_{0}^{1} R^{\text {in }}\left(\mu_{t}^{\prime}\right) \exp \left(-2 \frac{\tau}{\mu_{t}^{\prime}}\right) \mu_{t}^{\prime} d \mu_{t}^{\prime}$,

where $R^{i n}\left(\mu_{t}^{\prime}\right)$ is the Fresnel coefficient for inner reflection.

The first term in Eq. (10) describes the sun glint from the water surface; the second one describes the light, multiply reflected between the pond bottom and its surface.

Thus, the BRDF of a melt pond $R_{\text {pond }}$ is determined by the melt water optical depth $\tau_{p}$ and by the spectral albedo $A_{b}$ of its bottom. The pond bottom is an ice layer characterized by the transport scattering coefficient $\sigma_{i c e}$ and the optical depth $\tau_{i c e}$ through formulas analogous to Eq. (5). These parameters constitute vector $X_{\text {pond }}=\left(\tau_{p}, \sigma_{\text {ice }}, \tau_{\text {ice }}\right)$ (see Table 1).

Finally, it is supposed that the surface consists of white ice (highly reflective) and melt ponds with area fraction $S$. The BRDF of the whole pixel is a linear combination:

$R=(1-S) R_{\text {ice }}+S R_{\text {pond }}$.

The described model of the summer ice reflection was verified with field data (Istomina, Heygster, et al., 2013) from the Polarstern cruise (Istomina, Nicolaus, et al., 2013) and from field observations (Polashenski et al., 2012). A more detailed description of modeling optical properties of summer ice will be published separately.

\subsection{Spectral channels}

The input data to the retrieval algorithm are the TOA (top-of-theatmosphere) radiance coefficients measured in the spectral channels of a satellite radiometer. We used the channels of radiometer MERIS (MEdium Resolution Imaging Spectrometer) on ENVISAT (Environmental Satellite), because it had a sufficient number of channels in the visible and the near IR range, which were not saturated by reflection from bright surfaces as ice or snow. MERIS was operational from April 2002 until ENVISAT stopped its mission in April 2012, so we have a full decade of data to process. All further description will refer to the 
Table 2

MERIS spectral channels. The channels used in the algorithm are shown in bold and italic.

\begin{tabular}{|c|c|c|c|c|}
\hline \# & Center (nm) & Width (nm) & Use & Feature \\
\hline 1 & 412.5 & 10 & $\begin{array}{l}\text { Cloud mask, } \\
\text { Iterative procedure }\end{array}$ & \\
\hline 2 & 442.5 & 10 & $\begin{array}{l}\text { Separation of bright pixels, } \\
\text { Cloud mask, } \\
\text { Iterative procedure }\end{array}$ & \\
\hline 3 & 490 & 10 & $\begin{array}{l}\text { Separation of bright pixels, } \\
\text { Iterative procedure }\end{array}$ & \\
\hline 4 & 510 & 10 & Separation of bright pixels & \\
\hline 5 & 560 & 10 & & Ozone absorption \\
\hline 6 & 620 & 10 & & Ozone absorption \\
\hline 7 & 665 & 10 & & Ozone absorption \\
\hline 8 & 681.25 & 7.5 & Iterative procedure & \\
\hline 9 & 708.75 & 10 & & Water vapor absorption \\
\hline 10 & 753.75 & 7.5 & $\begin{array}{l}\text { Cloud mask, } \\
\text { Iterative procedure }\end{array}$ & \\
\hline 11 & 760.625 & 3.75 & Cloud mask & Oxygen absorption \\
\hline 12 & 778.75 & 15 & Iterative procedure & \\
\hline 13 & 865 & 20 & $\begin{array}{l}\text { Cloud mask, } \\
\text { Separation of the melting ice pixels, } \\
\text { Iterative procedure }\end{array}$ & \\
\hline 14 & 885 & 10 & $\begin{array}{l}\text { Cloud mask, } \\
\text { Iterative procedure }\end{array}$ & \\
\hline 15 & 900 & 10 & & Water vapor absorption \\
\hline
\end{tabular}

MERIS channels; however the algorithm can be easily adjusted to any appropriate satellite sensor, especially to the Ocean and Land Color Instrument (OCLI) on Sentinel-3 scheduled for launch in late 2014. The MERIS channels and their usage in the MPD algorithm are shown in Table 2. For clarity the channels used in the iterative procedure are given in bold; the channels used in the preprocessing are given in Italic.

The atmospheric contribution to the spectrometer signals needs to be taken into account in the retrieval procedure. The satellite data have to be corrected for four factors: scattering and absorption by aerosols and gases. Scattering and absorption by aerosols, as well as the molecular scattering, have much weaker spectral selectivity than gas absorption. The two main atmospheric gases with notable effect on the TOA signals in the spectral region of interest are ozone and water vapor. At the same time the concentrations and the altitude profiles of these gases are most changeable and uncertain. That is why the channels affected by these gases were excluded from the retrieval algorithm (they can be used in preprocessing, though).

Channel 11 was excluded because it corresponds to the R-branch of the oxygen absorption band ( $760.625 \mathrm{~nm}$ ). Channels 4 to 7 were also excluded because they are affected by the ozone absorption band. Ozone absorption is not very strong in this range; however, it becomes notable with oblique incidence typical for polar regions. Although channel 4 was excluded from the iterative procedure, it is used in the preprocessing of the input data. The remaining channels $(1-3,8-10,12-14)$ are not affected by ozone absorption. Channel 15 was excluded because it matches the water vapor absorption line at $900 \mathrm{~nm}$. The influence of water vapor absorption in channel 9 is not obvious a priori, but our further investigations (see Section 3.2.1) showed that the estimation of pond fraction in a pixel is affected by the atmospheric water vapor if channel 9 is included into the processing scheme. With exclusion of channel 9 the effect of water vapor on the retrieved pond fraction becomes negligible. Finally, the following channels are used in the iteration procedure: $1,2,3,8,10,12,13,14$, and channels 4 and 11 are used for preprocessing (see Eq. 14).

\subsection{MPD algorithm structure}

The flowchart of the MPD algorithm is presented in Fig. 1.

1. The input to the algorithm is the MERIS level 1B data with the spatial resolution of $1 \mathrm{~km} \times 1 \mathrm{~km}$ at nadir, including the radiance coefficients
$R_{i}$ at channels $i=1,2,3,4,8,10,11,12,13,14$, and the solar and observation angles (zenith and azimuth). Also the relevant information on atmosphere and surface state can be entered from an input file.

2. The data is sent to the three independent blocks:

a. Atmospheric correction preprocessing block;

b. Separation of the sea-ice pixels;

c. Setting the bounds for ice and pond parameters.

3. The core of the algorithm is the iterative procedure (see Section 2.3.4) for retrieving ice and pond parameters $X_{i c e}$ and $X_{\text {pond }}$ (see Table 1 ) and pond fraction $S$.

4. The resulting values of $X_{i c e}, X_{\text {pond }}$, and $S$ are used to calculate the spectral albedo of the pixel.

5. Output is the values of melt pond fraction, spectral albedo, and estimation of retrieval error in every pixel.

Hereinafter these procedures are described in more detail.

\subsubsection{Atmospheric correction preprocessing block}

The atmospheric correction preprocessing is organized in four steps (Fig. 1):

1. If there are relevant data on the state of the atmosphere, such as aerosol load, temperature or pressure profiles, these data can be entered into the calculation. Else, the default models are used. The default model for the molecular atmosphere defines the altitude profiles of temperature, pressure, and gases concentration, depending on the month and the latitude, similar as done in the radiative transfer model SCIATRAN (Rozanov, Rozanov, Kokhanovsky, \& Burrows, 2014). The default aerosol model is the Arctic Background aerosol (Tomasi et al., 2007).

2. The atmospheric reflectance $r_{i}$ and transmittance $t_{i}$ are calculated for the used set of wavelengths ( $i$ is the channel number) with the radiative transfer code RAY (Tynes et al., 2001). The reflectance $r_{i}$ is an array of two values: $R^{a t m}$ the atmospheric path radiance coefficient, and $r_{a}$, the atmospheric hemispheric reflectance when diffusely illuminated from below. The transmittance $t_{i}$ is an array of four values: $t_{0}(\theta), t_{0}\left(\theta_{0}\right), t_{d}(\theta)$, and $t_{d}\left(\theta_{0}\right)$, which are the quasidirect (subscript ' 0 ') and diffuse (subscript 'd') atmosphere transmittances when illuminated with a directional beam at incident angles $\theta$ and $\theta_{0}$, respectively.

3. The values of $r_{i}$ and $t_{i}$ are stored for every pixel and channel used. In our algorithm we suppose that the atmosphere is homogeneous for 


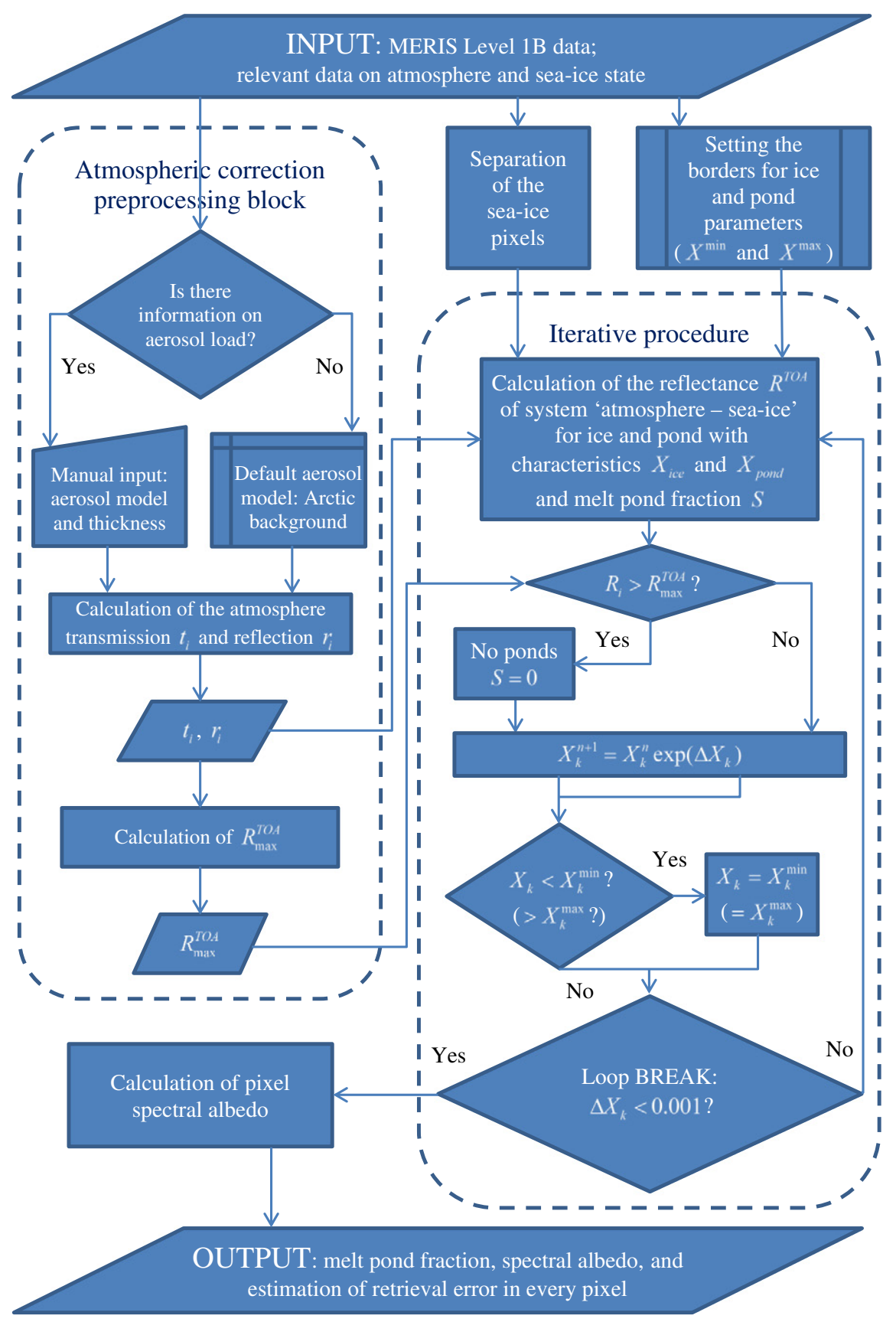

Fig. 1. Flowchart of the MPD algorithm.

the whole scene, but the values of $r_{i}$ and $t_{i}$ for different pixels differ, because of the observation geometry. These values are used later to calculate the TOA (top of the atmosphere) radiance coefficients.

4. Values of $r_{i}$ and $t_{i}$ are used to calculate the maximal TOA radiance coefficient $R_{\text {max }}^{T O A}$. It is the TOA radiance coefficient calculated with the same BRDF but with no absorption in any spectral channel. It is obtained by Eq. (26) (see below), with $r(\theta)=r\left(\theta_{0}\right)=r=1$ and $R$, calculated with the RAY code. This value $\left(R_{\max }^{T O A}\right)$ is used later in the iterative procedure as a threshold.

\subsubsection{Separation of the sea-ice pixels}

The separation of sea ice pixels works in two steps. First, the ocean pixels are identified by applying the landmask, using the geolocation data. Then, the following criteria are used to separate the ice pixels (Schlundt et al., 2011):

a. Brightness criterion:

$$
R_{2}, R_{3}, R_{4} \geq 0.3
$$

is used to separate bright pixels to discard open water.

b. Spectral neutrality criterion:

$$
\frac{R_{1}}{R_{2}}<1.04
$$

c. MERIS differential snow index (MDSIX) criterion:

$\frac{R_{13}-R_{14}}{R_{13}+R_{14}}>0.01$. 
Criteria (14)-(15) separate white surfaces, which can be snow, ice, or cloud. Criterion (16) discards the cloudy pixels. Pixels not satisfying criteria (14)-(16) are discarded.

d. An additional threshold is used to screen out high clouds, using the MERIS Level $1 \mathrm{~b}$ reflectances at wavelengths $753 \mathrm{~nm}$ and $760 \mathrm{~nm}$. These are bands 10 (oxygen A reference) and 11 (oxygen A absorption). To identify the cloud free pixels we detect pixels where the oxygen absorbs light within the whole atmosphere column as opposed to cloudy pixels where the absorption occurs only within the small fraction of the atmosphere column, namely, above the cloud. To do so we use the ratio:

$\frac{R_{11}}{R_{10}}<0.27$

Visual analysis of several dozen daily averages showed improved cloud screening and decreased amount of cloud edges and high thin clouds within the resulting product as compared to the product without use of this threshold.

\subsubsection{Setting the bounds for ice and pond parameters}

In order to avoid unphysical values for ice and pond parameters, the bounds are set to the values:

$$
\begin{aligned}
& S^{\max }=1.0, \\
& \tau_{w i}^{\min }=5.0, \\
& a_{e f f}^{\min }=30.0 \mu m, a_{e f f}^{\max }=10000.0 \mu \mathrm{m}, \\
& \tau_{p}^{\min }=0.0005, \\
& \sigma_{i c e}^{\min }=0.1 \mathrm{~m}^{-1}, \quad \sigma_{i c e}^{\max }=5.0 \mathrm{~m}^{-1}, \\
& \tau_{i c e}^{\min }=0.4, \tau_{i c e}^{\max }=6.0
\end{aligned}
$$

Value $S^{\max }=1.0$ is obvious (the melt pond fraction is less or equal to 1 ). The limiting case $S=1$ is treated as water saturated surface.

The lower bound for the optical thickness of ice $\tau_{w i}^{\min }$ determines the lowest value of ice albedo in the range $450-500 \mathrm{~nm}$ at directional or diffuse incidence through Eqs. (8) and (9), respectively. Typical white ice albedo values of $0.75-0.8$ in this spectral region, as observed by Perovich et al. (2002), correspond to the optical thicknesses $\tau_{w i}$ in the range of approximately 8.0-12.0 for the sun zenith angle of $65^{\circ}$ in Eq. (8). So, if not going beyond the case of white bare ice, one should take the bounds:

$$
\tau_{w i}^{\min }=8.0, \tau_{w i}^{\max }=12.0
$$

However, the values from Eq. (19) restrict the scope of the algorithm strongly. E.g., it completely excludes snow that can have the albedo value close to 1 in this spectral region for a semi-infinite $\left(\tau_{w i} \rightarrow \infty\right)$ layer. That is why, in order to include the snow covered ice into the scope, we remove the restriction on the upper bound for $\tau_{w i}$.

Conversely to snow, the darker types of ice can be included into the scope by decreasing the lower bound $\tau_{w i}^{\min }$. E.g. wet ice can often occur in conditions of melt onset. We call 'wet ice' the situation when the air pores in the upper layer of ice are mainly filled with water. In this case the scattering layer becomes much darker (albedo decreases) because of the lower optical thickness (e.g., 2.0). Thus, in order to include wet ice in the retrieval procedure one should set the lower bound to, e.g., 2.0. However, this change requires a certain amount of caution. As $\tau_{w i}$ decreases and $a_{\text {eff }}$ increase (the case of wet ice), the reflectance spectrum of ice approaches that of a melt pond. In this case ponds and ice become undistinguishable in the visible and near IR range. This does not affect strongly the albedo, but makes it impossible to retrieve the melt pond fraction. That is why, for the season of developed melting, when melt ponds on white ice can be easily identified, we use the lower bound $\tau_{w i}^{\min }=5.0$, which provides the lowest white ice albedo of 0.6 and higher in the blue-green region of the spectrum.

The other bounds for ranges of the retrieved parameters serve as additional regularization of the MPD algorithm and are set to correspond to values observed in nature (see Istomina, Heygster, et al., 2013).

In this block, as well as in that for the atmosphere, the relevant data can be used to change the default settings for values (18) in the input file. E.g., if a user knows that the ice type is perfect white ice (or e.g. snow-covered), the lower bound $\tau_{w i}^{\min }$ can be increased. If it is known that the ponds are mature, the lower bound $\tau_{p}^{\min }$ can be increased, and so on.

\subsubsection{The iterative procedure}

If the pixel is classified by criteria (14)-(16) as ice or snow, and not cloud, the radiance coefficients $R_{i}$ at channels $i=1,2,3,8,10,12,13,14$, as well as the solar $\left(\theta_{0}, \varphi_{0}\right)$ and observation $(\theta, \varphi)$ angles (zenith and azimuth), are used for further processing.

The pixel is characterized by the white ice and melt ponds parameters, shown in Table $1\left(X_{i c e}=\left(\tau_{w i}, a_{e f f}, \alpha_{y p}\right)\right.$ and $\left.X_{\text {pond }}=\left(\tau_{p}, \sigma_{i c e}, \tau_{i c e}\right)\right)$, and pond area fraction $S$. All these parameters constitute the vector $\mathbf{X}$ specifying the physical state of the surface:

$\mathbf{X}=\left(S, \tau_{w i}, a_{e f f}, \alpha_{y p}, \tau_{p}, \sigma_{i c e}, \tau_{i c e}\right)$

The iterative procedure is based on the Newton-Raphson method (Press, Teukolsky, Vetterling, \& Flannery, 1992) and comprises the following steps (see Fig. 1).

1. Brightness test:

$R_{i}>R_{\max }^{T O A}(i)$

If test (21) is true, the chosen model of ice BRDF and the atmospheric state cannot provide such high values of the TOA radiance coefficients. In this case we conclude that there are no melt ponds in this pixel, because melt ponds can only decrease reflection, i.e.

$S=0$

and further evaluation concerns the ice parameters $X_{i c e}$ only. In this case the pixel gets the attribute 'TOO_BRIGHT' as a flag.

If test (21) is false, all parameters (20) are included in the further processing.

2. Initialization of the state-vector $\mathbf{X}$ to the starting values:

$S=0.5$

$\tau_{w i}=\max \left(\mathrm{T}_{w i}, 5\right)$

$a_{\text {eff }}=3333 \mu \mathrm{m}$

$\alpha_{y p}=0.3 \mathrm{~m}^{-1}$;

$\tau_{p}=.01$

$\sigma_{\text {ice }}=1.5 \mathrm{~m}^{-1}$;

$\tau_{\text {ice }}=\min \left(\tau_{\text {wi }} / 3, \tau_{\text {ice }}^{\max }\right)$.

Here $\mathrm{T}_{w i}$ is the auxiliary value:

$\mathrm{T}_{w i}=4 \frac{\mathrm{g}(\theta) \mathrm{g}\left(\theta_{0}\right)}{R_{\max }^{T O A}(3)-R_{3}}-4$,

with $g(\theta)$ defined in Eq. (2).

Formula (24) is the rough estimation of the ice optical thickness, derived from Eq. (7) for channel 3, corresponding to $490 \mathrm{~nm}$. In this estimation the effect of the atmosphere is neglected. 
3. Initialization of the increments $\Delta \mathbf{X}$ :

$$
\begin{aligned}
& \Delta S=0.0005 \\
& \Delta \tau_{w i}=0.1 ; \\
& \Delta a_{e f f}=3 \mu \mathrm{m} ; \\
& \Delta a_{y p}=0.003 \mathrm{~m}^{-1} \\
& \Delta \tau_{p}=10^{-5} \\
& \Delta \sigma_{i c e}=0.01 \mathrm{~m}^{-1} \\
& \Delta \tau_{i c e}=0.01
\end{aligned}
$$

4. The radiometer signals on the top of the atmosphere $R_{i}^{T O A}$ are calculated for the given surface state $\mathbf{X}$. The functional dependence $R_{i}^{T O A}(\mathbf{X})$ is based on Eqs. (2)-(5). An approximate formula is used to calculate the TOA radiances with the known pixel BRDF and the atmosphere reflectance and transmittance:

$$
\begin{aligned}
R^{T O A}= & R^{a t m}+t_{0}(\theta)\left(R-\frac{r(\theta) r\left(\theta_{0}\right)}{r}\right) t_{0}\left(\theta_{0}\right) \\
& +\frac{\left(t_{0}(\theta) r(\theta)+t_{d}(\theta) r\right)\left(t_{0}\left(\theta_{0}\right) r\left(\theta_{0}\right)+t_{d}\left(\theta_{0}\right) r\right)}{r\left(1-r_{a} r\right)}
\end{aligned}
$$

where $R^{a t m}, t_{0}(\theta), t_{0}\left(\theta_{0}\right), t_{d}(\theta)$, and $t_{d}\left(\theta_{0}\right)$ are defined at Section 2.3.1, $R$ is the surface BRDF, $r(\theta)$ and $r\left(\theta_{0}\right)$ are the pixel albedo at direct incidence, $r$ is the pixel albedo at diffuse incidence. Eq. (26) is obtained under the following assumptions: the light transmitted by the atmosphere is considered as a sum of the direct (quasi-direct) and diffuse light and the light reflected by the atmosphere when illuminated from below is considered as completely diffuse. This formula is a modification of one, derived by Tanré, Herman, and Deschamps (1983) for atmospheric correction.

5. The matrix of logarithm derivatives of $R_{i}^{T O A}$ are numerically calculated for every component of vector $\mathbf{X}$ :

$$
\mathbf{M}=\left(M_{i k}\right)=\left(X_{k} \frac{\partial R_{i}^{T O A}}{\partial X_{k}}\right)
$$

6. The new value of vector $\mathbf{X}$ in the $(n+1)^{\text {th }}$ iteration step is calculated by:

$$
X_{k}^{n+1}=X_{k}^{n} \exp \left(\Delta X_{k}\right)
$$

where $\Delta \mathbf{X}$ is defined as:

$$
\Delta \mathbf{X}=\operatorname{pinv}\left(\mathbf{M}, \lambda_{\min }\right) *\left(\mathbf{R}-\mathbf{R}^{n}\right),
$$

$\operatorname{pinv}\left(\mathbf{M}, \lambda_{\min }\right)$ is the Moore-Penrose pseudoinverse of matrix $\mathbf{M}$, calculated using the singular value decomposition by level $\lambda_{\min }$ (Press et al., 1992), when any singular values less than $\lambda_{\min }$ are treated as zero. $\mathbf{R}=\left(R_{i}\right)$ is the vector of measured values, $\mathbf{R}^{n}=\left(R_{i}^{T O A}\right)$ is the vector of values, calculated on the $n^{\text {th }}$ iteration step.

7. If any of the new values $X_{k}$ is outside the bounds defined by Eq. (18), this parameter is assigned the bound value and is no longer changed. Its increment is set to zero:

$$
\Delta X_{k}=0
$$

The situation with $S=1$ is treated as extensive melting of ice when the surface is water saturated.

8. The iterative loop is terminated when the condition

$$
\Delta X_{k}<0.001
$$

is met for all $k$. Usually the iteration process converges after $4-5$ steps.

\section{Algorithm implementation}

\subsection{Internal verification}

For the verification of the MPD algorithm, a closed numerical experiment has been performed. It consists of the successive solution of the direct and inverse problem and the comparison of the initial (considered as 'true') and retrieved values. The point of this experiment is to detect the intrinsic error of the retrieval algorithm. The problem of the pond fraction retrieval belongs to the class of ill-posed problems and like many inverse problems it needs regularization. The MPD algorithm uses the singular values decomposition as a regularization method (see Eq. 29). That is why, although the same function $R_{i}^{T O A}(\mathbf{X})$ is used both for direct and inverse problem, the retrieval results differ from the initial 'true' values.

Thus the signals in the MERIS spectral channels were simulated for a set of ice pixels, each one being characterized by its own vector $\mathbf{X}=$ $\left(S, \tau_{w i}, a_{e f f}, \alpha_{y p}, \tau_{p}, \sigma_{i c e}, \tau_{i c e}\right)$, for a few typical situations shown in Table 3 as the 'true' data. In Table 3 and Figs. 2-6 some results of the retrieval of the pond fraction and the pixel albedo with the MPD algorithm are presented.

The retrieval is shown for five different situations. In all considered cases the true pond fraction is 0.4. This value was chosen as an example, because this is the case when both ponds and ice contribute significantly to the reflection, and because the simulations show that the retrieval error is close to maximal about this value. The first case in Table 3 represents the most frequently occurring situation, when the pixel consists of the 'standard' white ice and light blue melt pond (Eicken et al., 2004; Perovich et al., 2002, 2009; Polashenski et al., 2012). In this case the retrieved values are very close to the true ones, because this situation is the initial scope of the algorithm.

The second case presents the situation of very bright ice, covered with a layer of snow. In the developed approach snow matches the same microphysical model as white ice. The difference is that a snow layer has much greater optical thickness $\tau_{w i}$ and much lower effective

\begin{tabular}{|c|c|c|c|c|c|c|c|}
\hline Parameter & $\tau_{w i}$ & $a_{\text {eff }}(\mu \mathrm{m})$ & $\alpha_{y p}\left(\mathrm{~m}^{-1}\right)$ & $\tau_{p}$ & $\sigma_{i c e}\left(\mathrm{~m}^{-1}\right)$ & $\tau_{\text {ice }}$ & $S$ \\
\hline \multicolumn{8}{|c|}{ White ice E' light pond } \\
\hline True & 8.5 & 3333. & 0.1 & 0.016 & 1.0 & 3.0 & 0.40 \\
\hline Retrieved & 7.8 & 3140. & 0.29 & 0.010 & 1.1 & 3.3 & 0.401 \\
\hline \multicolumn{8}{|c|}{ Bright ice (snow covered) E light pond } \\
\hline True & 534. & 289. & 0.53 & 0.016 & 1.0 & 3.0 & 0.40 \\
\hline Retrieved & 24. & 582. & 0.37 & 0.023 & 4.1 & 6.0 & 0.33 \\
\hline \multicolumn{8}{|c|}{ White ice E' dark pond } \\
\hline True & 8.5 & 3333. & 0.1 & 0.013 & 0.2 & 0.5 & 0.40 \\
\hline Retrieved & 5 & 4886. & 0.3 & 0.007 & 1.0 & 0.93 & 0.24 \\
\hline \multicolumn{8}{|c|}{ Bright ice (snow covered) E' dark pond } \\
\hline True & 534. & 289. & 0.53 & 0.013 & 0.2 & 0.5 & 0.40 \\
\hline Retrieved & 10. & 1090. & 0.33 & 0.012 & 5.0 & 1.7 & 0.17 \\
\hline \multicolumn{8}{|c|}{ White ice E light pond \& $3 \%$ random error } \\
\hline True & 8.5 & 3333. & 0.1 & 0.016 & 1.0 & 3.0 & 0.40 \\
\hline Retrieved & 7.6 & 3670. & 0.29 & 0.008 & 0.66 & 4.0 & 0.38 \\
\hline
\end{tabular}
grain size $a_{\text {eff }}$ (see Table 3 ). In this case the retrieval is a bit worse than in the 'standard' case but is still acceptable. The retrieved pond fraction is 0.33 instead of 0.4 .

The blue colored light ponds are quite good for retrieval, because of their clearly recognizable spectral behavior. The cases with the dark ponds provide much greater retrieval errors, because the dark melt ponds have weak spectral dependence and lower reflectance. E.g., in the third case (white ice-dark pond) the retrieved pond fraction is 0.24 , i.e., is considerably underestimated. As dark ponds reduce the pixel albedo notably all over the spectrum, the reflection pattern of a

Table 3

Examples of the retrieval for some typical situations (see Table 1 for the explanation of symbols). Pond fraction values are given in bold. 


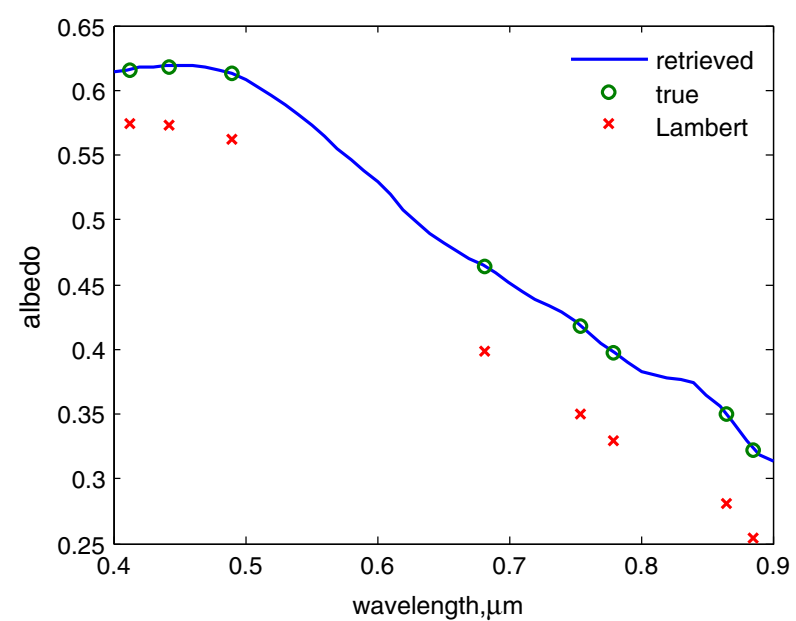

Fig. 2. Retrieved spectral albedo of a pixel consisting of white ice and light pond $(S=0.4)$. True albedo (o); albedo, retrieved with the MPD algorithm (curve), the albedo, retrieved within the Lambert approximation $(\mathrm{x})$.

mixed pixel with a certain amount of dark ponds is almost the same as that of a mixed pixel with darker ice and smaller pond fraction. These situations are hardly distinguishable in the visible range.

An even more pronounced effect is demonstrated in the fourth case: bright (snow covered) ice and dark melt pond, where the pond fraction is underestimated more than twice. However, this is a rare situation. The dark pond is a mature pond, i.e., the pond formed in the process of the developed melting. Fresh snow nearby could arise from a snowfall, which is a rare event in mid-summer.

Finally, the last (fifth) case shows the retrieval in the presence of the measurement error of $\pm 3 \%$. It is seen that all retrieved parameters are very close to the values retrieved in the first case when the error is absent. This is due to the fact that the pseudo-inverse matrix works as the least-squares approach, partially smoothing out the random errors.

Figs. 2-6 present the spectral albedo of the surface (true and retrieved). The crosses show the spectral albedo, retrieved within the Lambert approximation, i.e., with no regard to the BRDF of white ice and ponds. The first and most important conclusion is that the MPD algorithm provides accurate retrieval of the spectral albedo in all considered cases, even in the situations with dark ponds when the error of the melt pond fraction retrieval is maximal. The second feature seen from Figs. 2-6 is following: the spectral albedo is retrieved much better with the MPD algorithm than within the conventional algorithms using

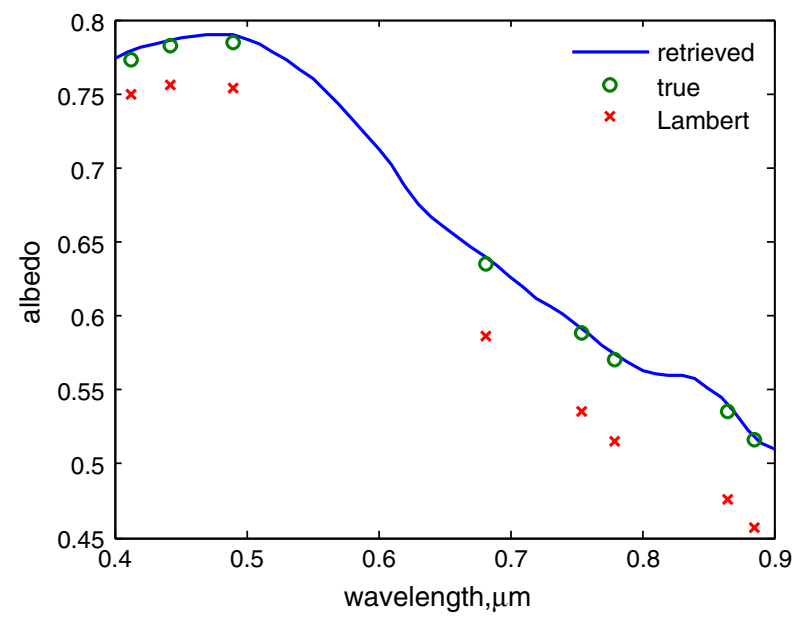

Fig. 3. Retrieved spectral albedo of a pixel consisting of snow covered ice and light pond $(\mathrm{S}=0.4)$.

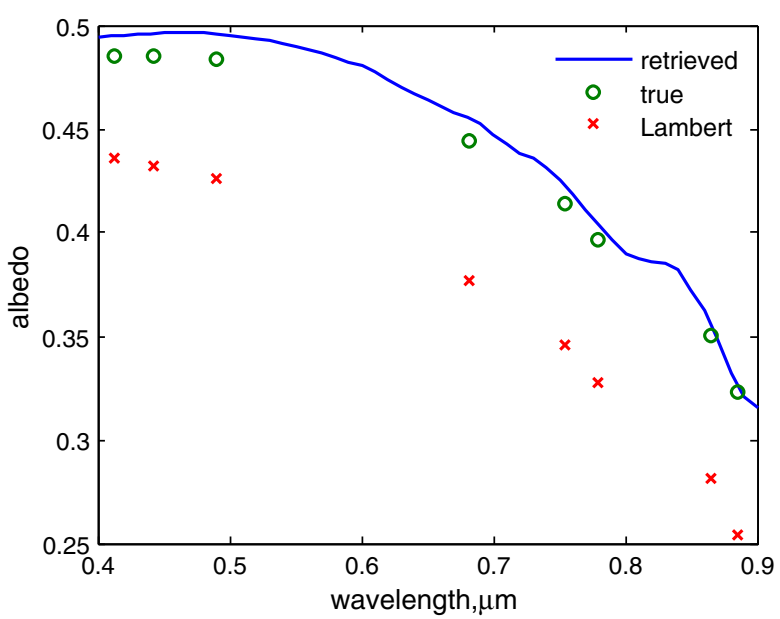

Fig. 4. Retrieved spectral albedo of a pixel consisting of white ice and dark pond $(S=0.4)$.

the Lambert approximation for surface reflection. The use of this conventional approach leads to underestimations of the albedo at about 0.05 all over the spectral range, whereas the error of the MPD retrieval in the worst case ('bright ice-dark pond', see Fig. 5) is 0.01 and lower in all other considered cases.

\subsection{Sensitivity of the MPD algorithm to the atmospheric model}

The MPD algorithm includes a procedure for atmospheric correction, embedded in the iterative scheme. As mentioned in Section 2.3.1 it uses a predefined atmospheric model that can be adjusted if one has the relevant data on the profiles of pressure and temperature aerosol load, and gas (mainly, ozone and water vapor) content. Such information is not always available, in which case the default model is used. That is why it is so important to check the stability of the retrieval results with respect to the used atmosphere model.

Rayleigh scattering is not very sensitive to the thermodynamic state and it is easy to take it into account. The effect of ozone absorption is discarded in the MPD algorithm by the channels selection. The most uncertain atmospheric factors are the water vapor content and the aerosol load.

\subsubsection{Sensitivity to the water vapor content}

To figure out the effect of the uncertainty in the prescribed water vapor content in atmosphere used for the retrieval we made the

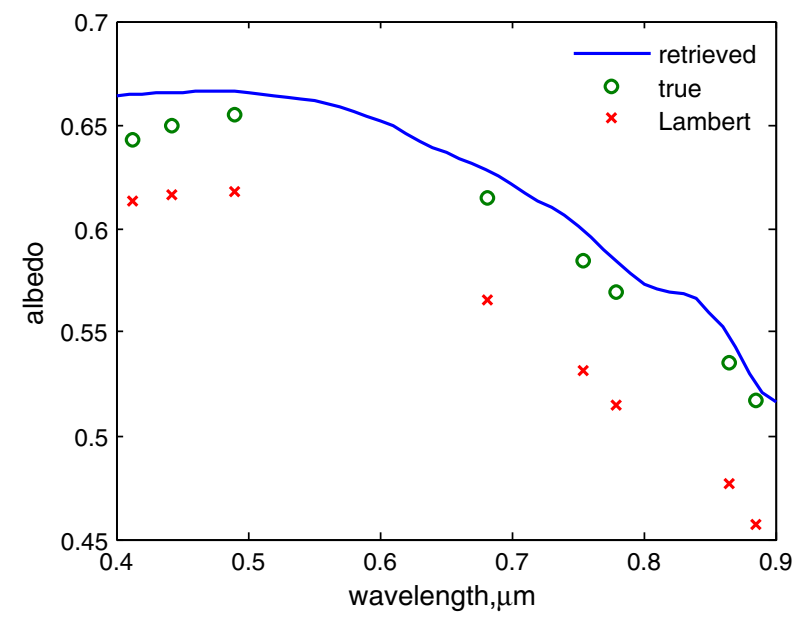

Fig. 5. Retrieved spectral albedo of a pixel consisting of snow covered ice and dark pond $(\mathrm{S}=0.4)$. 


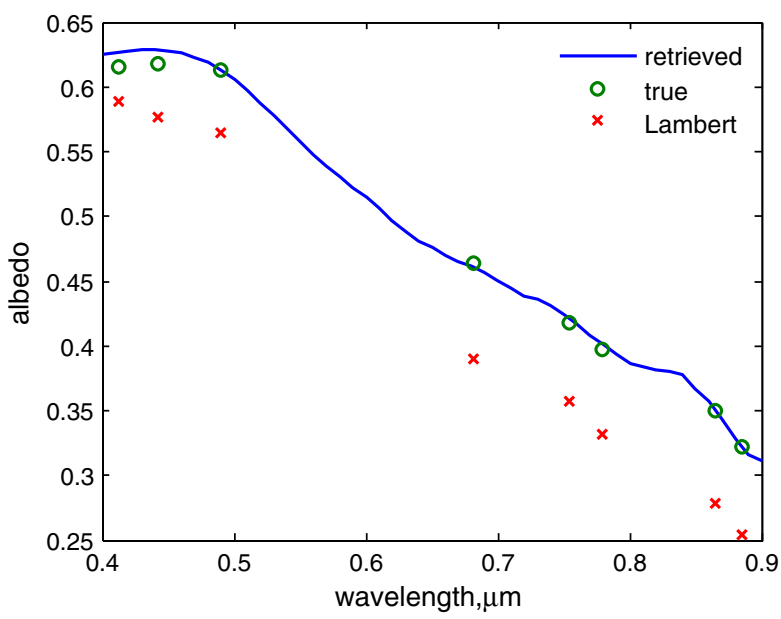

Fig. 6. Retrieved spectral albedo of a pixel consisting of white ice and light pond $(S=0.4)$ and the measurement error of $\pm 3 \%$.

following numerical experiment. We took the MERIS scene of Arctic sea ice (MER_RR_1PPBCM20080607_224801_000001522069_00173_ 32792_0519.N1, date: June 7, 2008) and chose the two ice pixels: $80^{\circ} 36^{\prime} \mathrm{N}, 140^{\circ} 04^{\prime} \mathrm{W}$ and $80^{\circ} 08^{\prime} \mathrm{N}, 141^{\circ} 03 \mathrm{~W}$.

For these two pixels we ran the MPD algorithm in two versions: with and without including channel 9 in the retrieval. For both versions two values of the water vapor content were used: the default value of $2.13 \mathrm{~g} \mathrm{~cm}^{-2}$ and the increased value of $3.3 \mathrm{~g} \mathrm{~cm}^{-2}$. The results of this experiment are shown in Table 4. The retrieved pond fraction is affected by the prescribed water vapor content if channel 9 is included into the iterative scheme. As seen from Table 4 the effect of water vapor on the retrieved pond fraction is negligible, if the iterative scheme does not use channel 9. This is the reason why channel 9 was excluded from the iterative procedure in the MPD retrieval.

\subsubsection{Sensitivity to the aerosol model}

The retrieval of aerosol optical thickness above such bright surfaces as ice or, even more, snow from satellite data is associated with great difficulties. That is why in this case it is reasonable to use the predefined aerosol models for atmospheric correction procedure. In order to estimate the error, caused by the uncertainties of aerosol load, we have investigated the sensitivity of the retrieval to the aerosol model and its optical thickness. The satellite radiometer signals were simulated with the RAY code (Tynes et al., 2001) for typical Arctic aerosols (see Table 5). The type of aerosol determines the spectral behavior of the extinction and scattering coefficients and hence the aerosol optical thickness (AOT) at any wavelength through its value at $0.5 \mu \mathrm{m}$ (Tomasi et al., 2007).

The signals at the radiometer input were simulated for various aerosol types and loads (see Table 5). The retrievals from these simulated satellite signals were performed with the atmospheric correction using the Arctic Background aerosol for all simulated cases. The results of the retrieval are shown in Figs. 7 and 8. They demonstrate the sensitivity of the melt pond fraction (Fig. 7) and spectral albedo (Fig. 8) retrieval to the inaccuracy of aerosol model (aerosol type and optical thickness) used for atmospheric correction. It is seen that the MPD

Table 4

Effect of water vapor on the retrieved pond fraction in version of algorithm with and without the 9th channel.

\begin{tabular}{llllll}
\hline & \multicolumn{2}{l}{ With channel 9 } & & \multicolumn{2}{l}{ Without channel 9 } \\
\cline { 2 - 4 } \cline { 5 - 6 } Water vapor content & $2.13 \mathrm{~g} \mathrm{~cm}^{-2}$ & $3.3 \mathrm{~g} \mathrm{~cm}^{-2}$ & & $2.13 \mathrm{~g} \mathrm{~cm}^{-2}$ & $3.3 \mathrm{~g} \mathrm{~cm}^{-2}$ \\
\hline Melt pond fraction. Pixel 1 & 0.159 & 0.172 & & 0.162 & 0.166 \\
Melt pond fraction. Pixel 2 & 0.112 & 0.196 & & 0.120 & 0.123
\end{tabular}

Table 5

Arctic aerosol models and their optical thickness (Tomasi et al., 2007).

\begin{tabular}{ll}
\hline Type & AOT at $0.5 \mu \mathrm{m}$ \\
\hline Background aerosol & 0.015 \\
Dense aerosol & 0.080 \\
Arctic haze & 0.150 \\
Asian dust & 0.200 \\
Fire smokes & 0.300 \\
\hline
\end{tabular}

retrieval is weakly sensitive to the aerosol load and the aerosol model for the typical Arctic aerosols. This is particularly true for the albedo retrieval. Thus, for the procedure of atmospheric correction in the process of the retrieval it is acceptable to use the Arctic Background model. However, if any additional data about the aerosol optical thickness and/or model are available, they can be easily adjusted within the MPD software.

\subsection{Estimation of the retrieval error}

Within the MPD software some estimations of the accuracy of the retrieval are performed. Namely, the root mean square difference between measured and retrieved signals $\sigma$

$\sigma=\sqrt{\frac{1}{m} \sum_{i}\left(R_{\text {meas }}^{i}-R_{\text {ret }}^{i}\right)^{2}}$

is computed for every pixel and included in the output file. Here $m$ is the number of channels used (in the current implementation of the MPD algorithm $m=8$ ).

This value is a good estimate for the absolute error $\Delta A$ of the albedo retrieval:

$\Delta A=2 \sigma$,

$A_{\text {ret }}=A_{\text {true }} \pm \sigma$

The relative error of the pond fraction retrieval (except the case $\mathrm{S}=0$ ) can be estimated from Eq. (29) that is a standard system of linear equations (see, e.g., Appendix in Malinka \& Zege, 2007):

$\frac{\Delta S}{S}=\frac{\sigma}{\lambda_{\min } \sqrt{n}}$,

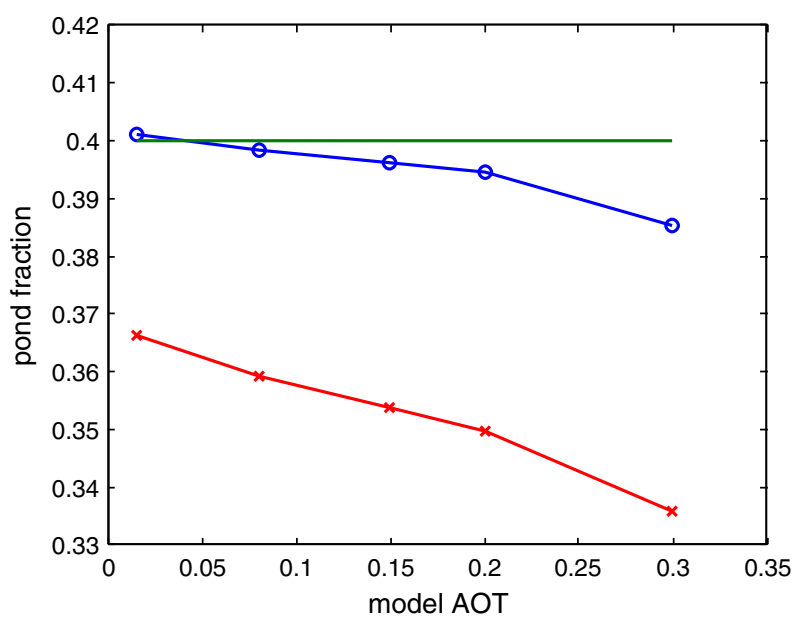

Fig. 7. Retrieved melt pond fraction vs. aerosol optical thickness. AOT corresponds to the type of aerosol (see Table 5). The retrieval is made with the Arctic Background model. The true melt pond fraction (-), the pond fraction, retrieved with the Arctic Background aerosol (o-), and the pond fraction, retrieved without atmospheric correction (x-). 


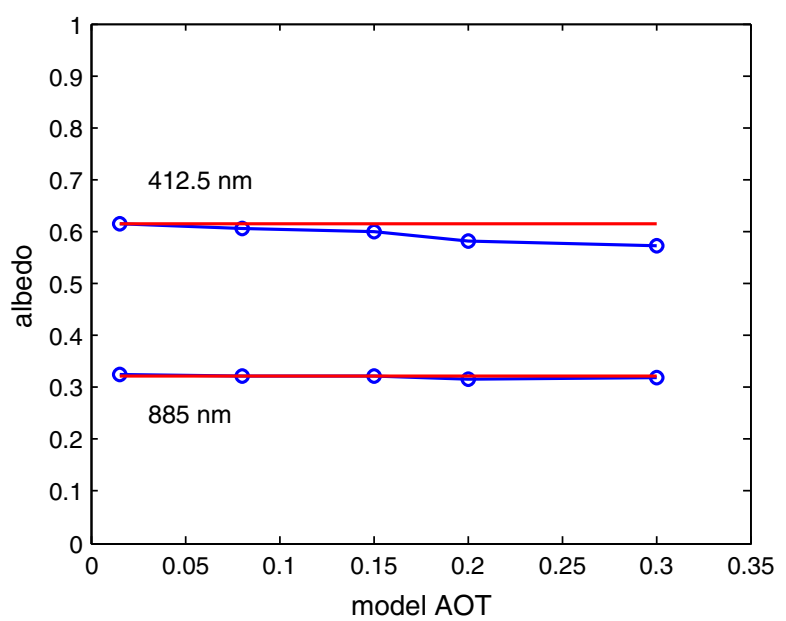

Fig. 8. Retrieved spectral albedo vs. predefined aerosol optical thickness. AOT corresponds to the type of aerosol (see Table 5). The retrieval is made with the Arctic Background model. The true (-) and retrieved (o-) albedo values.

where $n$ is the number of parameters to retrieve. In the current MPD implementation:

$n=7 ; \quad \lambda_{\min }=0.0075$.

\subsection{Validation with the field data}

The validation of the both albedo and melt pond fraction retrieval has been performed on an extensive set of airborne, ship-based and in situ campaigns for various ice and weather conditions. The comparison is most informative for the cases of landfast or multiyear sea ice (high ice concentration, no thrashed overturned ice floes) for the situation where ponds are surrounded with white ice. The full MPD validation description can be found in (Istomina et al., 2014). This Section presents a typical example of the validation efforts.

Among all the used datasets, the best quality and spatial coverage was given by aerial measurements. The flight was performed on 06/06/2008 within the MELTEX field campaign (Birnbaum et al., 2009) over the landfast ice. The time difference between satellite and airborne overflight was limited to $1.5 \mathrm{~h}$. The albedo measurements were performed from an aircraft with two Eppley pyranometers mounted in a fixed position to measure the broadband hemispheric down- and upwelling shortwave radiation. The collocation to the satellite data was performed by calculating an orthodromic distance of every pixel within a satellite swath to a given aerial measurement point and collecting aerial points with the minimum distance to the center of a chosen satellite pixel. This results in about 500 albedo measurements per pixel. The melt pond fraction was extracted from preselected quality-assured airborne images that were classified into surface classes with the maximum likelihood method. The number of points per flight is in the order of hundreds with about 5 images per satellite pixel collocated to the satellite data, same as in the albedo measurements. An example of comparison for both albedo and melt pond fraction is shown in Fig. 9.

The left panel of Fig. 9 shows the comparison of the airborne derived melt pond fraction to the MPD retrieved values. Number of points is $\mathrm{N}=88$. It is seen that the melt pond fraction is overestimated a little in the retrieval, as compared to the aerial observations. The highest overestimation is in the range of small fractions. However, this effect is present in other algorithms as well (for instance, see Fig. 11 in Rösel et al., 2012). This overestimation can be explained by the presence of blue ice or sediments from the coast, because the airborne measured albedo of these pixels is quite low $(<0.4)$. However, in total, the correlation is satisfactory $(\mathrm{R}=0.70)$.

As it might be expected, the situation is much better for the albedo retrieval. The right panel shows the comparison of broadband albedo obtained by airborne pyranometer (the wavelength range of the instrument is $285 \mathrm{~nm}$ to $2.8 \mu \mathrm{m}$ ) to the shortwave albedo obtained by narrowto-broadband conversion of the retrieved spectral albedo at 4 channels ( $490 \mathrm{~nm}, 560 \mathrm{~nm}, 665 \mathrm{~nm}$, and $865 \mathrm{~nm}$ ), as suggested by Liang (2001), Stroeve et al. (2005), Gao, Schaaf, Jin, Lucht, and Strahler (2003). Number of points is $N=279$, correlation coefficient $R=0.90$, root-meansquare difference RMS $=0.032$. Due to the fact that the measured broadband albedo is dependent on the atmospheric conditions and illumination geometry (including the flight time), the absolute difference of measured and retrieved value is less informative than the correlation of these values that allows evaluating the melt state of the surface.

\subsection{Implementation of the algorithm for bulk processing}

The MPD algorithm is currently implemented for bulk data processing at the Institute of Environmental Physics, University of Bremen. The entire historic MERIS dataset 2002-2012 has been processed. The processing chain is implemented as a Python script and, besides the actual running of the MPD software, includes subsetting the full orbit to the satellite scene of interest and performing radiometric corrections (equalization to reduce detector-to-detector and camera-to-camera systematic radiometric differences, smile correction (Bourg, D'Alba, \& Colagrande, 2008) to reduce the CCD-induced variations of wavelength from pixel to pixel, and radiometric re-calibration), using the BEAM
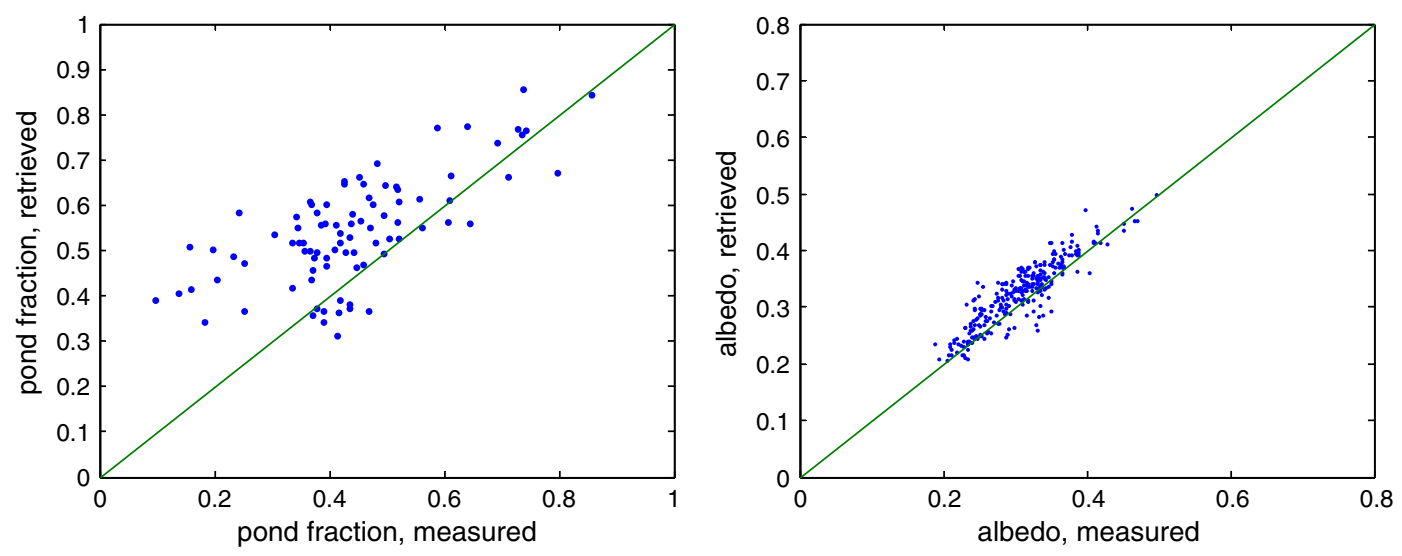

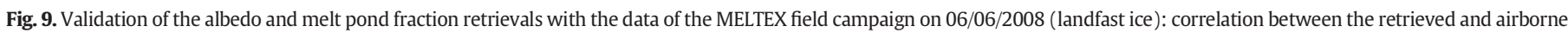
classified melt pond fractions (left), $\mathrm{R}=0.70, \mathrm{RMS}=0.15$; correlation between the retrieved and airborne measured broadband albedo (right), $\mathrm{R}=0.90, \mathrm{RMS}=0.032$. 

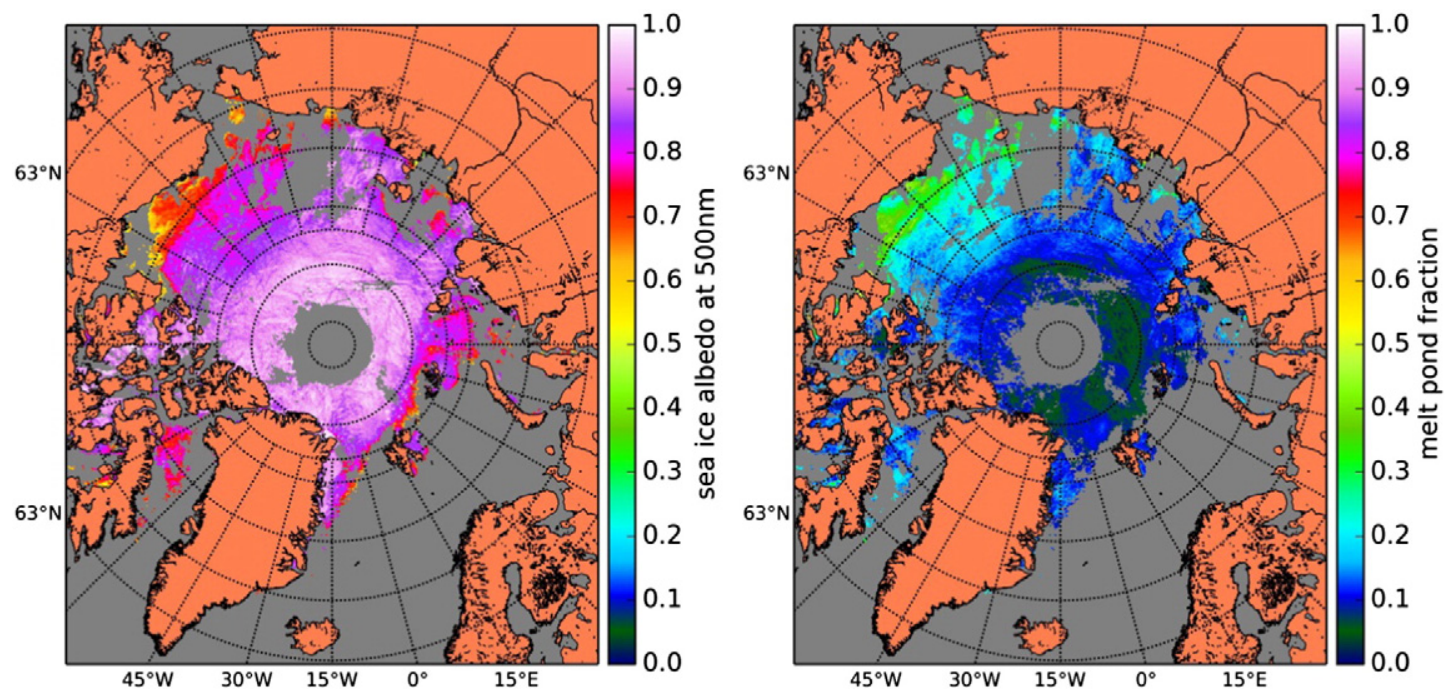

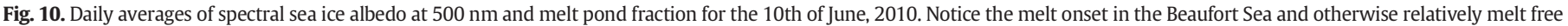
Arctic Ocean.

command line tool (www.brockmann-consult.de/cms/web/beam/). To produce daily averaged output, the data obtained from all the orbits for the given day is gridded into a $12.5 \mathrm{~km}$ polar stereographic grid (the so-called NSIDC grid). The resulting values are the daily averages of melt pond fraction, spectral albedo and their standard deviations. These values are stored as four variables into a NetCDF file.

An example of the daily averaged melt pond fraction and sea ice albedo at $500 \mathrm{~nm}$ for the 10th of June, 2010 is shown in Fig. 10. On this day, the Arctic Ocean is still relatively melt free at the higher latitudes. Melt onset starts in the more southern Beaufort Sea. In this region, especially closer to the shore on the first year ice and land fast ice, the melt pond fraction reaches 0.4 , which is typical for smooth and level ice before pond drainage. The spectral albedo is correspondingly lower in this region.

\section{Conclusion}

The new algorithm to retrieve the melt pond fraction and spectral albedo of the summer ice in Arctic has been developed. It is substantially different from the known state-of-the-art algorithms (Rösel et al., 2012; Tschudi et al., 2008) as it is based on the newly developed optical model of the sea ice reflection and does not use the a priori reflectance spectra of sub-pixels constituents. Conversely, these spectral reflectances are corrected during the iteration process. The algorithm uses an embedded procedure of atmospheric correction and takes into account the ice BRDF, which is of great importance for the satellite remote sensing of the Arctic basin because of the low sun.

The optical models of sea ice and melt pond reflection used in this algorithm were successfully verified with existing experimental data and measurements for various types of Arctic summer ice (Istomina, Heygster, et al., 2013). The experimental spectra of ice and melt ponds used are taken from the databases of the Cold Regions Research and Engineering Laboratory (CRREL, USA) (Polashenski et al., 2012) and from the Polarstern expedition 2012 measurements (University of Bremen) (Istomina, Nicolaus, et al., 2013). The algorithm verification with the in situ measurements and aerial data is published separately (Istomina et al., 2014).

Basing on the analysis of experimental data, the bounds for values, specifying the physical state of the surface, were established. These bounds determine the variability of the ice/pond properties observed in situ. The variation of the bounds allows expanding or straitening the scope of the algorithm, even to the limit where the spectral reflection coefficients of ice and ponds are fixed. In this case the MPD algorithm becomes analogous to the state-of-the-art ones (Rösel et al., 2012; Tschudi et al., 2008). On the other hand, the extension of the permissible bounds allows including situations, which were not initially in the scope, e.g., to describe the wet, water saturated ice surface or thin ice. However, these types of ice have reflectance spectra that are very close to those of melt ponds. This fact does not strongly affect the albedo retrieval, but makes it impossible to distinguish ponds and ice. The same applies to the case of blue ice that has spectral reflectance similar to that of ponds. However, this problem is well known and is inherent to any algorithm, working with data in the visible and IR range (Tschudi et al., 2008). That is why the algorithm is supposed to be stable when the ice is quite bright, providing the albedo of about 0.6 and higher in the blue-green region of the spectrum.

The numerical simulations show that the MPD algorithm provides accurate estimates of the fractional composition of a pixel in the case of developed melting when pixels constituents are white ice and light melt ponds. It is shown that more accurate MPD results are obtained for pixels with light blue ponds than with dark ones. Despite the errors of the retrieved pond fraction in the case of dark ponds can exceed $50 \%$ in the worst cases, the spectral albedo is retrieved with high accuracy for any type of ice and ponds (the error is not greater than 0.01). This feature relates to the fact that the MPD algorithm takes into account the angular dependence of the reflection, while the retrieval with the Lambert approximation usually underestimates the albedo by about 0.05 all over the spectral range. Thereby, the accuracy of the MPD retrieval of the spectral albedo of Arctic summer ice from satellite data meets the requirements of many application including climatological ones.

The algorithm was implemented as computer code that we call Melt Pond Detector (MPD). Currently, the MPD code is arranged as a Linux console application, and works in the MERIS processing chain in the University of Bremen, providing a comprehensive melt pond data product based on the complete MERIS data set (2002-2012). These retrievals provide historical data on the process of Arctic ice melting, which is so important for understanding the climate changes in the Arctic. It is planned to implement the MPD code for processing data of other optical satellite sensors such as OCLI on Sentinel 3 to be launched in the near future.

\section{Acknowledgment}

The authors would like to express their special appreciation and thanks to Prof. Donald Perovich and Dr. Chris Polashenski from CRREL 
for their extremely valuable consulting and providing the reflection spectra of the Arctic ice during melting period. We would also like to thank the scientific shipboard party of the RV Polarstern cruise IceArc2012 for making the field observations of ice albedo possible.

This work was supported by the project no. 262922 SIDARUS (Sea ice downstream services for Arctic and Antarctic Users and Stakeholders), financed by the European Union in the 7th Framework Programme for Research and Development.

\section{References}

Barry, R. G. (1996). The parameterization of surface albedo for sea ice and its snow cover. Progress in Physical Geography, 20(1), 63-79.

Birnbaum, G., Dierking, W., Hartmann, J., Lüpkes, C., Ehrlich, A., Garbrecht, T., et al. (2009). The Campaign MELTEX with Research Aircraft "POLAR 5" in the Arctic in 2008. Berichte zur Polar- und Meeresforschung Reports on Polar and Marine Research, 593, 3-85.

Boetius, A., et al. (2013). Export of algal biomass from the melting Arctic sea ice. Science, 339(6126), 1430-1432. http://dx.doi.org/10.1126/science.1231346.

Bourg, L., D'Alba, L., \& Colagrande, P. (2008). MERIS smile effect characterisation and correction. ESA technical note (http://earth.eo.esa.int/pcs/envisat/meris/documentation/ MERIS_Smile_Effect.pdf).

Bricaud, A., Morel, A., \& Prieur, L. (1981). Absorption by dissolved organic matter of the sea (yellow substance) in the UV and visible domains. Limnology and Oceanography, 26(1), 43-53.

Curry, J. A., Schramm, J. L., \& Ebert, E. E. (1995). Sea-ice albedo climate feedback mechanism. Journal of Climate, 8(2), 240-247.

Dethloff, K., Rinke, A., Benkel, A., Køltzow, M., Sokolova, E., Kumar Saha, S., et al. (2006). A dynamical link between the Arctic and the global climate system. Geophysical Research Letters, 33, L03703. http://dx.doi.org/10.1029/2005GL025245.

Doronin, Yu.P. (1970). Thermal interaction of the atmosphere and the hydrosphere in the Arctic. Edited by E. P. Borisenkov. Translated by Dov Lederman. Published by Israel Program for Scientific Translation. 1st edition: Main Administration of the Hydrometeorological Service, Arctic and Antarctic Scientific Research Institute.

Eicken, H., Grenfell, T. C., Perovich, D. K., Richter-Menge, J. A., \& Frey, K. (2004). Hydraulic controls of summer Arctic pack ice albedo. Journal of Geophysical Research, 109, C08007. http://dx.doi.org/10.1029/2003JC001989.

Flocco, D., Feltham, D. L., \& Turner, A. K. (2010). Incorporation of a physically based melt pond scheme into the sea ice component of a climate model. Journal of Geophysical Research, 115, C08012. http://dx.doi.org/10.1029/2009JC005568.

Flocco, D., Schroeder, D., Feltham, D. L., \& Hunke, E. C. (2012). Impact of melt ponds on Arctic sea ice simulations from 1990 to 2007. Journal of Geophysical Research, 117, C09032. http://dx.doi.org/10.1029/2012JC008195.

Gao, F., Schaaf, C., Jin, Y., Lucht, W., \& Strahler, A. (2003). Deriving albedo from coupled MERIS and MODIS surface products. Proceedings of MERIS user workshop 2003, ESA, ESRIN, Frascati, Italy, 10-13 November 2003.

Grenfell, T. C., \& Maykut, G. A. (1977). The optical properties of ice and snow in the Arctic basin. Journal of Glaciology, 18(80), 445-463.

Heygster, G., Alexandrov, V., Dybkjær, G., Girard-Ardhuin, F., von Hoyningen-Huene, W., Katsev, I. L., et al. (2012). Remote sensing of sea ice: advances during the DAMOCLES project. The Cryosphere, 6, 1411-1434. http://dx.doi.org/10.5194/tc-61411-2012.

Hunke, E. C., Hebert, D. A., \& Lecomte, O. (2013). Level-ice melt ponds in the Los Alamos sea ice model, CICE. Ocean Modelling, 71, 26-42.

Istomina, L., Heygster, G., Huntemann, M., Schwarz, P., Birnbaum, G., Scharien, R., et al. (2014). The melt pond fraction and spectral sea ice albedo retrieval from MERIS data: validation and trends of sea ice albedo and melt pond fraction in the Arctic for years 2002-2011. The Cryosphere Discussions, 8, 5227-5292. http://dx.doi.org/10. 5194/tcd-8-5227-2014.

Istomina, L., Heygster, G., Zege, E., Malinka, A., Prikhach, A., \& Katsev, I. (2013). Albedo and meltpond analysis: validation and calibration of the MPD retrieval using sea ice and melt pond albedo spectra measured during Polarstern cruise IceArc2012. Scientific report no. D4.4 to project SIDARUS (Sea Ice Downstream services for Arctic and Antarctic Users and Stakeholders), grant no. 262922 of the 7th Framework Programme for Research and Development (http://sidarus.nersc.no/content/ public-deliverables)

Istomina, L., Nicolaus, M., \& Perovich, D. (2013). Spectral albedo of sea ice and melt ponds measured during POLARSTERN cruise ARK XXII/3 (IceArc) in 2012. PANGAEA dataset. Bremen: Institute for Environmental Physics, University of Bremen. http://dx.doi. org/10.1594/PANGAEA.815111.

Kokhanovsky, A. A., \& Zege, E. P. (2004). Scattering optics of snow. Applied Optics, 43, 1589-1602. http://dx.doi.org/10.1364/A0.43.001589.

Køltzow, M. (2007). The effect of a new snow and sea ice albedo scheme on regional climate model simulations. Journal of Geophysical Research, 112, D07110. http://dx. doi.org/10.1029/2006JD007693.

Liang, S. (2001). Narrowband to broadband conversion of land surface albedo. I. Algorithms. Remote Sensing of Environment, 76, 213-238

Light, B. (2010). Theoretical and observational techniques for estimating light scattering in first-year Arctic sea ice. In A. Kokhanovsky (Ed.), Light scattering reviews 5. Single light scattering and radiative transfer (pp. 331-391). Berlin: Springer.

Light, B., Eicken, H., Maykut, G. A., \& Grenfell, T. C. (1998). The effect of included particulates on the spectral albedo of sea ice. Journal of Geophysical Research, 103(C12), 27,739-27,752.

Lüpkes, C., Gryanik, V. M., Rösel, A., Birnbaum, G., \& Kaleschke, L. (2013). Effect of sea ice morphology during Arctic summer on atmospheric drag coefficients used in climate models. Geophysical Research Letters, 40, 1-6. http://dx.doi. org/10.1002/grl.50081.
Malinka, A. (2014). Light scattering in porous materials: Geometrical optics and stereological approach. Journal of Quantitative Spectroscopy and Radiation Transfer, 141, 14-23.

Malinka, A., \& Zege, E. (2007). Possibilities of warm cloud microstructure profiling with multiple-field-of-view Raman lidar. Applied Optics, 46(35), 8419-8427.

Markus, T., Stroeve, J. C., \& Miller, J. (2009). Recent changes in Arctic sea ice melt onset, freezeup, and melt season length. Journal of Geophysical Research, 114, C12024. http://dx.doi.org/10.1029/2009JC005436.

Mobley, C. D., Cota, G. F., Grenfell, T. C., Maffione, R. A., Pegau, W. S., \& Perovich, D. K. (1998). Modeling light propagation in sea ice. IEEE Transactions on Geoscience and Remote Sensing, 36(5), 1743-1749.

Nazintsev, Y. L. (1964). Thermal balance of the surface of the perennial ice cover in the central Arctic (in Russian). Works of Arctic and Antarctic Scientific Research Institute (Tr. Arkt. Antarkt. Nauchno-Issled. Inst.), 267. (pp. 110-126), 110-126.

Nicolaus, M., Gerland, S., Hudson, S. R., Hanson, S., Haapala, J., \& Perovich, D. K. (2010) Seasonality of spectral albedo and transmittance as observed in the Arctic Transpolar Drift in 2007. Journal of Geophysical Research, 115, C11011. http://dx.doi.org/10.1029/ 2009JC006074

Perovich, D. K. (1996). The optical properties of sea ice. Report 96-1. Hanover (NH, USA): US Army Cold Regions Research and Engineering Laboratory (CRREL) (www.dtic.mil/ cgi-bin/GetTRDoc?AD =ADA310586).

Perovich, D. K., Grenfell, T. C., Light, B., Elder, B. C., Harbeck, J., Polashenski, C., et al. (2009). Transpolar observations of the morphological properties of Arctic sea ice. Journal of Geophysical Research, 114, C00A04. http://dx.doi.org/10.1029/2008JC004892.

Perovich, D. K., Grenfell, T. C., Light, B., \& Hobbs, P. V. (2002). Seasonal evolution of the albedo of multiyear Arctic sea ice. Journal of Geophysical Research, 107(C10), 8044

Perovich, D. K., Richter-Menge, J. A., Jones, K. F., \& Light, B. (2008). Sunlight, water and ice: extreme Arctic sea ice melt during the summer of 2007. Geophysical Research Letters, 35, L11501.

Pirazzini, R. (2008). Factors controlling the surface energy budget over snow and ice. Academic dissertation in meteorology. Helsinki: Finnish Meteorological Institute.

Pistone, K., Eisenmann, I., \& Ramanathan, V. (2014). Observational determination of albedo decrease caused by vanishing Arctic sea ice. Proceedings of the National Academy of Sciences of the United States of America, 111(9), 3322-3326. http://dx.doi.org/10.1073/ pnas.1318201111.

Polashenski, C., Perovich, D., \& Courville, Z. (2012). The mechanisms of sea ice melt pond formation and evolution. Journal of Geophysical Research, 117, C01001. http://dx.doi. org/10.1029/2011JC007231.

Press, W. H., Teukolsky, S. A., Vetterling, W. T., \& Flannery, B. P. (1992). Numerical recipes in C. The art of scientific computing (2nd ed.). Cambridge: Cambridge University Press.

Rösel, A., Kaleschke, L., \& Birnbaum, G. (2012). Melt ponds on Arctic sea ice determined from MODIS satellite data using an artificial neural network. The Cryosphere, 6, 431-446.

Rozanov, V. V., Rozanov, A. V., Kokhanovsky, A. A., \& Burrows, J. P. (2014). Radiative transfer through terrestrial atmosphere and ocean: Software package SCIATRAN. Journal of Quantitative Spectroscopy and Radiation Transfer, 133, 13-71.

Schlundt, C., Kokhanovsky, A. A., von Hoyningen-Huene, W., Dinter, T., Istomina, L., \& Burrows, J. P. (2011). Synergetic cloud fraction determination for SCIAMACHY using MERIS. Atmospheric Measurement Techniques, 4, 319-337.

Schröder, D., Feltham, D. L., Flocco, D., \& Tsamados, M. (2014). September Arctic sea-ice minimum predicted by spring melt-pond fraction. Nature Climate Change, 4 353-357. http://dx.doi.org/10.1038/nclimate2203.

Serreze, M. C., Barrett, A. P., \& Cassano, J. J. (2011). Circulation and surface controls on the lower tropospheric temperature field of the Arctic. Journal of Geophysical Research, 116, D07104.

Serreze, M. C., Walsh, J. E., Chapin, F. S., III, Osterkamp, T., Dyurgerov, M., Romanovsky, V., et al. (2000). Observational evidence of recent change in the northern high latitude environment. Climatic Change, 46, 159-207.

Shindell, D., \& Faluvegi, G. (2009). Climate response to regional radiative forcing during the twentieth century. Nature Geoscience, 2, 294-300. http://dx.doi.org/10.1038/ ngeo473.

Stroeve, J. Box, J, Gao, F, Liang S., Nolin, A \& Schaaf, C. (2005). Accuracy assessment of the MODIS 16-day albedo product for snow: Comparisons with Greenland in situ measurements. Remote Sensing of Environment, 94, 46-60. http://dx.doi.org/10 1016/j.rse.2004.09.001

Tanré, D., Herman, M., \& Deschamps, P. Y. (1983). Influence of the atmosphere on space measurements of directional properties. Applied Optics, 21, 733-741.

Tomasi, C., et al. (2007). Aerosols in polar regions: A historical overview based on optica depth and in situ observations. Journal of Geophysical Research, 112, D16205. http:// dx.doi.org/10.1029/2007JD008432.

Tschudi, M. A., Maslanik, J. A., \& Perovich, D. K. (2008). Derivation of melt pond coverage on Arctic sea ice using MODIS observations. Remote Sensing of Environment, 112(5), 2605-2614.

Tynes, H., Kattawar, G. W., Zege, E. P., Katsev, I. L., Prikhach, A. S., \& Chaikovskaya, L. I. (2001) Monte Carlo and multi-component approximation methods for vector radiative transfer by use of effective Mueller matrix calculations. Applied Optics, 40, 400-412.

Untersteiner, N. (1990). Structure and dynamics of the Arctic Ocean ice cover. In A Grantz, L. Johnson, \& J. F. Sweeney (Eds.), The Arctic Ocean region (pp. 37-51). Boulder: Geol. Soc. of Am.

Warren, S. G., \& Brandt, R. E. (2008). Optical constants of ice from the ultraviolet to the microwave: A revised compilation. Journal of Geophysical Research, 113, D14220. http://dx.doi.org/10.1029/2007JD009744.

Wiebe, H., Heygster, G., Zege, E. P., Aoki, T., \& Hori, M. (2013). Snow grain size retrieva SGSP from optical satellite data: Validation with ground measurements and detection of snowfall events. Remote Sensing of Environment, 128, 11-20. http://dx.doi.org/10. 1016/j.rse.2012.09.007.

Zege, E. P., Ivanov, A. P., \& Katsev, I. L. (1991). Image transfer through a scattering medium. Heidelberg: Springer-Verlag.

Zege, E. P., Katsev, I. L., Malinka, A. V., Prikhach, A. S., Heygster, G., \& Wiebe, H. (2011) Algorithm for retrieval of the effective snow grain size and pollution amount from satellite measurements. Remote Sensing of Environment, 115(10), 2674-2685. 